\title{
Speculative Empiricism, Nature and the Question of Predatory Abstractions: A Conversation with Didier Debaise
}

\section{Didier Debaise}

Université libre de Bruxelles

\section{Thomas P. Keating (1)}

Linköping University

\begin{abstract}
In conversation' with Didier Debaise, this piece thinks transversally across Nature as Event (20I7a) and Speculative Empiricism (20I7b) to explore some of the key stakes in his philosophy, namely: the relationship between the task of thinking a speculative empiricism and the problem of the bifurcation of nature. Engaging with the themes of nature, abstraction, dualism, pragmatism, and the role of stories in dramatizing our sensitivity to the world, the conversation develops Debaise's contribution to theorising alternative modes of knowledge and experience capable of admitting those infra-sensible, inaudible, or imperceptible qualities of events. Distinctly, Debaise introduces here the problem of 'predatory abstractions' as one way to understand the problem of bifurcation. Ethically, the question of predatory abstractions makes new demands on the social sciences: to story new abstractions capable of deepening our experience of nature.
\end{abstract}

\section{Keywords}

abstractions, William James, pluralistic universe, speculative philosophy, universal mannerism, war machine, Alfred North Whitehead

\section{Introduction}

'Speculative empiricism', writes Didier Debaise (2017b: 164), 'is, before all else, a technical philosophy'. Suspicious of a priori schemas, it 
concerns techniques for investigating those aspects of experience "that are only vaguely perceived' (Debaise, 2017a: 29). Crucial to a speculative empiricism is a concern with creating abstractions suitable for grasping experience in its entirety. Philosophy, in this mode, "no longer moves from experience towards simplification but rather from simplification towards experience' (Debaise, 2017b: 163). In shifting from simplification to the munificence of experience, Debaise's philosophy marks a radical attempt to open philosophy up to a notion of experience that would be irreducible to perceptive and conscious qualities. And yet, what takes shape in Debaise's thought is not restricted to a theory of experience but includes another focus, at times backgrounding passages of his writing, on developing techniques of speculative thinking as an exploration into 'various ways of inhabiting the earth' (Debaise, 2020: 247).

Since co-founding the Groupe d'études constructivistes (GECo) at the Free University of Brussels with Isabelle Stengers in 2003, Debaise has emerged as a key contributor to debates on the politics of nature, the philosophy of individuation and ontogenesis, the status of the nonhuman, the question of problematization, and theorizations of creativity and pragmatism. Like Donna Haraway, Bruno Latour, Eduardo Viveiros de Castro, Déborah Danowski, and Philippe Descola, he is interested in rethinking certain ontological frames produced by 'nature' via alternative manners, gestures, and techniques of thought that seek to make room for minoritarian forms of knowledge and experience. Intersecting theoretical work by feminist scholars to recognize those diverse modes of knowledge practices already existing hic et nunc (Gibson-Graham, 1996), the question of realizing alternative registers of knowledge and experience seems for Debaise less about placing philosophy as a source of pure invention, or as a generator of new ideas ex nihilo. Instead, it concerns the sense that the possibility for alternative forms of knowledge and experience already exists in the immediacy of an experiential event. As Debaise and Stengers (2017: 15) put it: 'any experience, however factual, is saturated with interpretations, ideas and multiple links'.

As an exploration of alternative modes of thinking and experiencing, two of Debaise's books - Nature as Event (2017a) and Speculative Empiricism (2017b) - can be read as a continuation of a line of thought that intersects Alfred North Whitehead's (1978) notion of eternal objects, Raymond Ruyer's (2019) engagement with embryogenesis as a process of absolute formation, Gilbert Simondon's (2020) philosophy of individuation, and Deleuze and Guattari's (1994) writing on concepts as pure events. This genealogy does not simply state that the individual is a reductive figure but argues that philosophy entirely misapprehends genesis and processes of invention when it relies on individuated terms. Responding to this problem requires another approach to thought that 
grasps inventive processes and the genesis of events through different logics of explanation. Debaise contributes to this task by developing a notion of experience irreducible to the individuated forms of experience and consciousness. In doing so: 'What is needed is a philosophy that, in its very form, its ambition and its manners of relating to things, can grant due importance to the deeply plural experience of nature' (Debaise, 2017a: 77).

Considering the pursuit of a plural experience of nature as one of the hallmarks of Debaise's contribution to this genealogy of thought, it is worth noting here two stakes running through his philosophy. The first is that Debaise positions speculative empiricism as an entire approach for understanding immediate experience in its pluralism. Key to understanding speculative empiricism is the problem Debaise identifies through Whitehead and William James: that accounts of the multiplicity of experience tend to be reduced to a series of pre-given abstractions. Experience is poorly understood in philosophy when framed through other ready-made problems, such as 'perception, intention or consciousness' (Debaise, 2017b: 164) that misrecognize and exclude certain qualities. As with James' pragmatism, a speculative empiricism responds to this problem in considering itself a 'method' that aims to 'interpret everything' in experience (Debaise, 2017b: 17). As a method for making more of immediate experience, speculative empiricism offers an intriguing proposition for the social sciences: to explore techniques that remake those habits of thought that otherwise deaden our capacity to experience the immediacy of an event, and the possibilities for thinking otherwise produced therein.

The second stake is that Debaise (2017a) situates Whitehead's (1948) bifurcation of nature as the primary and most important problem for responding to dualist separation of nature and culture. If the dualist problem refers to the way nature becomes split into two irreconcilable realities (culture versus nature, human versus non-human, matter versus substance, etc.), then the bifurcation of nature would be a more fundamental problem since it refers to the primary 'gesture' that organizes 'how a single reality, nature, came to be divided into two distinct realms' (Debaise, 2017a: 7). As a gesture that produces certain abstractions, the bifurcation of nature works directly on immediate experience in concerning how the subject comes to categorize its experience of nature into primary and secondary qualities - including, for example, the 'reduction of matter to a localizable element' (Debaise, 2017a: 16). Beside this modern conception of nature lies what Debaise (2017a: 249) describes as a 'murky zone' that neither localizes matter in space and time nor reduces the category of nature to phenomenal experience, and instead contemplates an openness of nature in terms of its primary qualities irreducible to pre-given categories. As with research into the pluriverse (Savransky, 
2019), geophilosophical accounts of world-making (Viveiros de Castro, 2015), and biodesign practices (Williams and Collet, 2020), Debaise's engagement with bifurcation asks a series of epistemological questions about how to stretch our capacities for thinking imperceptible relations of nature:

What is a body when it is separated from its secondary qualities? How can we make sense of such a body, since we only have access to secondary qualities? What kind of knowledge would allow us to penetrate into the interior of these nonobservable qualities? (Debaise, 2017a: 15)

Moving between Nature as Event and Speculative Empiricism, this conversation aims to think transversally across these two stakes by exploring the interconnections between the task of speculative thinking and the problem of the bifurcation of nature. In speculative philosophy these interconnections take on a certain import, as Andrew Lapworth (2015: 2) notes, since they concern the way abstractions 'make our experience matter in a selective way through the foregrounding and backgrounding of different elements in sense-awareness'. What, then, does it take to exclude nothing from our experience of nature? What abstractions might enhance our capacity to think the whole of experience? What becomes of knowledge as a category if it no longer disqualifies the nonobservable and infra-sensible?

In pursuing some of these questions intersecting the two books, through the course of the conversation we encounter some of the ways the creation of abstractions becomes interwoven with the task of constructing certain kinds of stories. Resisting any normative sense of valuation, these stories would nonetheless be capable of creating sensitivities to what Debaise terms 'hidden or inaudible possibilities'. Uniquely, in what follows Debaise introduces the idea of 'predatory abstractions' or the capacity for abstractions to take on a dominant, operative quality as an all-terrain predatory war machine. Through the idea of predatory abstractions he poses questions about the ethical responsibilities evinced in pursuing a speculative empiricism - this 'monstrosity' of terms. There is, as Debaise notes, a 'speculative demand' sited in the task of generating new sensitives to the immediacy of an event. This speculative demand is a difficult one: it speaks to a moment of making stories that 'do not arise out of any a priori necessity' but that, due to their lack of pre-given necessity, perhaps provide a glimmer of an alternative, another way of perceiving an event, an uneasy perspective, or a more expansive sense of what else might be possible.

Thomas Keating: What I appreciate in your writing is your emphasis on making philosophy think about experience in its pluralism. That is, in 
tasking philosophy with thinking about how to remake modes of thought that reproduce dominant abstractions - be this certain ideas of 'nature' (often set against the notion of 'culture' and problematically used as a placeholder term for the idea of wilderness), or ideas about what gets counted as the 'empirical' (often set against the 'theoretical' and restricted to the act of field work and data capture). I am interested in the ways your philosophy makes certain demands of those interested in writing about nature from an expanded empirical field of experience. At the beginning of Nature as Event you note that 'the abstractions we construct, our very modes of thought are no longer able to deepen or develop our experience of nature' (Debaise, 2017a: 1). To begin, could you give me a sense of what it means to deepen our experience of nature and why this act of deepening our experience of nature is linked to the construction of abstractions?

Didier Debaise: It is maybe for me all the difference between the two books. I started to be more interested in what I call an 'ethology of abstractions', which means treating abstractions as beings with their own life, with their own stories, and their own moments of invention, with their trajectory and sometimes their fossilization. And what I am interested in more and more is the question of the effects of certain abstractions on our experiences. I do not think that there are any pure experiences emptied of all ideas, emptied of all abstractions. An experience, as specific [ponctuelle] as it might be, is saturated with abstractions. This question interests me particularly when dealing with the question of nature. According to a conception we have inherited, nature is the opposite of abstraction, which does not come under our constructions but would impose itself on us beyond the artifices of thought. What was in front of us, outside of all our constructions, that from the moment of construction enters into the order of the artificial and the cultural, this nature was precisely this space outside of our abstractions, outside of our reach, outside of our ideas. Nature would be that space of reality that is independent of the manner ${ }^{2}$ [manière] in which it is characterized, independent of the ways we link it together that would fall under the questioning subject and the human subject. It is this function of nature, which is not presented as falling under abstractions, that started to fascinate me more and more.

Reading work in the history of science - whether it is Lorraine Daston or people with whom I have worked a lot such as Isabelle Stengers or Bruno Latour - it seemed obvious to me that nature, the concept of nature, has at the same time a history. This is to say that there are times in which the idea of nature is invented. When we call nature this thing that is independent of our abstractions, this is something that is very historically situated in that it was established in the 17th century. This so-called objective, neutral nature is something that was invented 
historically and that was also invented geographically since it corresponds to the nature of the moderns in opposition to, or different to, the natures or the manners of articulating beings that one could find in other societies, or what Descola and Latour refer to as 'other collectives'.

What we considered to be this universal, timeless space - this common space beyond our concepts, this thing I was working on in connection with changes in anthropology, in the history of science, etc. - this appeared excessively situated both geographically and historically. I interrogated this moment when this idea of a nature as we know it is invented, and I was interested in all these gestures, which are experimental gestures. It is what I describe very strongly in Nature as Event. At the moment they are put into place, these gestures - I am thinking of gestures such as localization, such as bifurcation, which we may be able to come back to - give importance to certain factors of our experience. ${ }^{3}$ These gestures made it possible to articulate, to connect a whole series of beings, that there was a force in the implementation [mise en place] of these gestures that I call 'gestures of abstraction'. They had a force, a necessity. They made it possible to amplify, in a specific way, certain dimensions of our experience. Then they were extracted from the places, experiences, experiments that gave them their legitimacy. Due to a lack of attention to the connections that related them to the experiences they qualified, they were sometimes applied, without adjustment, without attention to other places and to other experiences. Whitehead has a very beautiful expression: he says the function of philosophy is to take care of our abstractions. ${ }^{4}$ Because we did not take care - we did not pay attention to the difference of place, to the difference of space, to the difference of time - we gave our abstractions a power that they do not have; they have become machines that have run empty [tourner à vide]. What made these abstractions necessary is that they had become beings that I call predatory abstractions, which is to say abstractions that disqualify, and which end up emptying out what they were supposed to qualify; they have come to empty our experiences rather than enrich them.

William James makes a distinction that I would like to take up in my account: there are abstractions that make the world thin and others that thicken it. If there is one trial [épreuve] that we can pass on to our ideas, it would be this: has it been the occasion of a thinning of our conditions of existence and of thought, or of a thickening? It is therefore at the level of abstractions that the distinction is made: there are abstractions whose effect is to thin the environment in which they take shape, as if they only found their reason and their effectiveness in the subtraction of qualities of concrete things - of their dependence on their environment, of the specific relationships they forge with others. There are, on the contrary, 
abstractions that thicken things, bring with them new dimensions, and highlight the fragile and eventful character of their existence.

We see it with the concept of nature. The concept of nature is an invention that could open our imagination beyond our experiences, which could open our experiences to other dimensions. In this sense, the concept of nature could be one of those notions that thickens our experience by adding new dimensions to it, and no doubt at one time it was an abstraction of this type. It has ended up running empty and has become a disqualification machine, an operator of subtraction, thinning out our experiences. So, this abstraction became a machine of disqualification of all the qualities of things that did not fall within the dimensions that we attributed to nature - namely, mathematical qualities, physical qualities, as if everything else came from superficial dimensions that did not belong to nature, namely aesthetic sense, moral sense, pleasure [jouissance], interests [intérêts], the sense of importance, and at the same time disqualification of all knowledge practices. I recall a phrase from Isabelle Stengers (2015: 98) that I like very much: 'We live in a veritable cemetery for destroyed practices'. Of all the practices of attention to these dimensions of beings - the practices of amateurs, of people who cultivated a care for things but who did not come under the knowledge that one could call the majority in the sense that they came to redouble the qualification of nature - all these practices have been disqualified. At the same time, nature has also become an enormous operator of the disqualification or colonization of Others. We consider that these other collectives, these other cultures, these other civilizations, approached more or less this notion that we, however, invented through abstractions that have run empty and that came, in a way, from a process of disqualification. That is what I meant in noting that nature no longer allows us to give depth and strength to our experience because where it was supposed to amplify, intensify, and broaden the sense of our experience, it has come to shrink and desertify it by permanently subtracting dimensions from our experience. Nature has become an operator of subtraction rather than an operator of addition and amplification, which could have made us sensitive to the experience of other collectives and other civilizations, but also to the multiplicity of factors, of experiences that belong to our own cultures.

TK: Something I wanted to pick up on is how the process of disqualification creates a loop in our thinking about nature that we cannot get out of. As you note, as well as being tied to certain aesthetic frames, certain moral frames, the question, or problem, of nature also concerns for you what Whitehead terms the bifurcation of nature. In Nature as Event you are careful to distinguish between Whitehead's notion of the bifurcation of nature and a wider question of the Cartesian dualism, which you understand as two distinct problems. I am interested in why it is that 
the bifurcation of nature is particularly important today given that a lot of recent work in the environmental humanities and philosophy has tended to focus on a critique of Cartesianism and the associated separation of experience into the human and non-human. Is it, perhaps, that the bifurcation of nature gives us a distinct problem to address those aesthetic and moral frames subject to a disqualification of nature?

DD: I will answer in two moments. The first is a continuation of what we have just talked about. I believe that the question of the disqualification produced by abstractions is an absolutely fundamental question because at the time I was writing, for example, Speculative Empiricism, I had the feeling that to work on speculative thought (to work on diagrams, abstractions, to work on the sense of imagination) was something quite different than working on political issues (on what makes bias, exclusion, the qualification of those who are legitimate to speak or occupy a position in a space). I think that this problem is still an effect of bifurcation, which is to say that there is not on the one side the place of abstractions, of ontology, of metaphysics, and then morals and politics [la politique] on another side. I tend to think that to question the meaning of abstractions is to question one of the main places of constitution of the political frameworks that we inherit. That is what interests me the most. How can something seemingly as neutral, or so 'innocent' to use the words of Donna Haraway (1988), as the question 'what is nature?' take on deeply political dimensions and become the point of exploration of veritable war machines of qualification and disqualification? It is this sense of the political that means today I would have no difficulty in saying that political questions are always ontological questions, and that to deal with ontology is to deal with values and politics. One way or another the separation of these two things is absolutely disastrous. Someone who says, 'I only do ontology, I am not interested in political questions', is just as dramatic as someone who would say 'I am interested in political questions and I leave to the others ontological and epistemological questions'. I think it is a disaster either way. It is this point that I try to be the most sensitive about and this is why, when I describe abstractions, more and more I use notions like predations, the space of non-innocence of our abstractions, and the disastrous effects of some aspects of abstractions. Michel Serres used the expression of a pharmakon: it is a whole pharmakon of abstraction. Abstractions have always begun by qualifying and intensifying practices that gave them all their reason and utility. It is the lack of attention, moving to other places, which turned them into an all-terrain predatory machine.

Now I come to the difference between bifurcation and dualism. Dualism is the manner through which the history of modern thought has been presented to us in general for a very long time now. The moderns would be dualists. They would think there is the mind on one side 
and matter on the other side, and that there would be two types of substances. When presented with dualism, the moderns are presented with a certain vision of the world: a dual ontology that would have been, at a push, invented by philosophers but that would come under a certain conception of the universe. Very little attention is paid to the reasons why the moderns have been dualistic. Why did they want dualism? Why did they make dualism sacred? I think that if there is something that the history of science teaches us it is that, before being dualists, the moderns are formed in very particular places, places where experiments occur. This is to say, places where we do not only describe and we do not observe but we provoke experimental situations. One of the experimental situations that is concomitant with the invention of modern science is the operation of bifurcation. The gesture by which we grasp a body (be it a physical body, a living body) and we extract (through a set of techniques and equipment, microscope, formalization, a set of technical devices [dispositifs] that will allow us to extract a quality that seemed obvious and immediately given in the observation) other body qualities that would be hidden from it. The whole question of the moderns is how to extract the so-called superficial or secondary qualities, to background these qualities a little so that we can create correlations between bodies, however different they may be. Whether a body is blue, red, or green, or whether it is rough or not will become superficial given a set of qualities common to that body. There is enormous efficiency in this gesture. This is to say that we can always extract the qualities of a body by an experimental operation. We are always entitled to do so. By doing this, one can connect a whole series of bodies that were not previously connected.

The big mistake of bifurcation is its reification; that is to say, the moment where we forget that we have made a gesture of extracting qualities and we act as if we have described heterogeneous qualities that in nature would be heterogeneous. This reification is something that is absolutely not demanded by the experimental gesture, but once it has taken place it has massive effects. This is where I, personally, situate the invention of dualism. That is to say that dualism is an image of thought that somehow sanctifies the difference that had been produced by bifurcation. Dualism never questions the causes of the production of dualism, which are not dualistic but are those of the bifurcation operation. The reason why it seems to me today absolutely essential to re-examine bifurcation, rather than the question of dualism, is that with the question of dualism we can always say that 'we are not dualist', we can always say that 'dualism is outdated', but we will continue to inherit the gestures that produced dualism. It seems to me that in moving towards these gestures that we find at all levels - no longer only in the sciences but in the divisions between aesthetics and ontology, the political and epistemological, between the moral and factual, between values and 
facts, etc. - all these great oppositions that we still continue to repeat and reproduce are all manifestations of bifurcation that would persist even if we removed dualism. We would still remain within these gestures. It is these gestures that are untenable because we feel that the experiences we are dealing with today are pluralist, heterogeneous, made up of hybrid beings with their own needs, their own manner of interacting with each other, and to reduce them to the question of primary or secondary quality, or matter or spirit, no longer makes much sense.

TK: If the problem is that these gestures are becoming reproduced today, is this why your concept of universal mannerism becomes so important in Nature as Event in that it becomes a way of thinking besides the bifurcation of nature? And in a sense, and you will have to forgive me if this is going too far, is universal mannerism a concept that understands nature in terms of immanence? Is it a way of thinking about an immanence of nature besides primary and secondary qualities?

DD: We are used to attributing to the human subject a certain number of qualities: intentionality, reflexive consciousness, sense of values, moral intentions, aesthetic taste, feelings, etc. My idea is that if we have these qualities we have no reason to consider that they would form a domain in their own right and that, on the contrary, they express something of beings themselves in that, simply, we cultivate them or that we have inherited them through certain modalities. What I call universal mannerism is to consider any being, any entity, a bundle of feeling. The manner of relating to other beings forms a perspective on other beings and is, in this sense, a subject in its own right. But clearly those modalities of expression, the modalities of sensation of feeling, are evidently not of the same order as those to which we give importance in our own mode of existence. It is a gesture that I would call speculative. For example, the notion of feeling something, of being affected by a milieu. Take feelings as they appear to us as one of our qualities: put its characteristics or this notion or this quality inside all beings and follow the manner in which beings are differentiated according to their greater or lesser intensity of feeling. I call mannerism something that comes under notions such as panexperientialism, which is to say the fact that everything, each entity whether human or non-human, has an experience and that what we call 'the real' is the multiplicity of interactions that these beings have from heterogeneous perspectives with each other. They fabricate from their interaction, from their mode of perception, sometimes without this coming under any meaning such as visual, auditory, or olfactory perception. Through their interactions they form a set of domains that we tend to call nature and that are, first of all, intersubjective relations. By intersubjective I mean not only human but infra-human and that we are one of these modalities (one of these forms of experience). As humans we give 
importance to certain qualities, to certain characteristics, but we are neither the model nor the standard, nor the finality.

What we gave to the notion of the subject we can deploy at all levels of reality while preserving the idea that it is according to distinct modalities. This is what I mean by mannerism. A universal mannerism is the idea that each being is in relation with other beings according to its own modalities and that these modalities form a perspective on the set of existing things. As William James (1920: 443-4) said, we have to think a universe composed 'of personal lives (which may be of any grade of complication, and superhuman or infrahuman as well as human), variously cognitive of each other [...], genuinely evolving and changing by effort and trial, and by their interaction and cumulative achievements making up the world'. To speak of mannerism is also to speak of a generalized perspectivism. These notions are quite concomitant.

TK: One final question on nature: given this rich articulation of universal mannerism - the sense that all entities have perceptive powers and are able to engage in self-enjoyment and a prehension of entities in the world - can there be any entities that exist outside of nature? Is there a concept of non-nature in your philosophy?

DD: More and more I detach myself from the word 'nature'. There is no use in deconstructing 'nature' because it is practical. It can be a simple convention and I have no problem with that, but from the moment we make nature into something that is supposed to be a way of articulating the composition of beings, I would keep my distance because its effects are much more harmful than the benefits that can be derived from it. More and more I use James' concept of a pluralistic universe, a pluralistic universe in the sense that it is a universe that is not defined by domains of existence or by common soil, but by what James calls superabundance. There is always more than what you think you are looking for, or what you think you can find. There is always more: too many relationships, too many connections, too many articulations. The pluralistic universe is the universe in which each time you believe you have achieved something you discover that there was more in it and never less. According to James' great maxim, radical empiricism must never exclude anything and, on the contrary, always add. A manner of qualifying adds a dimension, a way of relating adds a dimension.

The question that should interest us is not how to subject beings to a common space that would be nature, or how to bring them back by their analogies and their resemblance to a common background which would be this nature. The question we should ask ourselves is 'how to inhabit this pluralistic universe?' This is to say, how to circulate? How to make sense of the changes made? How to give meaning to our experiences? How to intensify them? How to recognize their importance in a universe that James describes as mobile and overabundant? That is, the future will 
never mirror the past, and our present is a present in abundance rather than in unity.

TK: In thinking about the connections between your philosophy and James' pluralistic universe, this is a good moment to focus on the notion of abstraction and the question of intensification, as well as the political actions that are associated with speculative philosophy today. I see a genealogy in your work linking Whitehead to thinkers like Gilbert Simondon and Raymond Ruyer, who critique substantialist models of thought that would position the individual as this terminal point for thinking about all kinds of inventive, individuating relations in space and time. What I find interesting in your writing is that you say quite clearly that you are not interested in inventing new abstractions ex nihilo. As you note in 'The Insistence of Possibles' (Debaise and Stengers, 2017), it is more the case that the possible already exists here and now, and the task of the speculator tends to be more of observation and of becoming more sensitive to those relations that are perhaps imperceptible, infrasensible, or at the edges of what we categorize as experience. What seems important is the way that you position speculation and the question of creating new abstractions as about intensifying our sensitivities to certain things. Would this be a fair reflection?

DD: The question is very fair and points to something I wanted to do by linking two terms which seemed absolutely contradictory, which formed a sort of oxymoron: empiricism and speculative thinking. One could not imagine two traditions more opposed to one another. One might wonder what interest there is in creating this sort of monstrosity. I think it is something that marks a somewhat singular trajectory compared to the current legacies of speculative thought, which would not necessarily be found in this demand of empiricism that I hold that I sometimes also read as pragmatism. I think one could just as easily refer to speculative empiricism as a speculative pragmatism. What did I want to do by connecting these two things? The insistence on experience is the insistence on the fact that we are dealing with situations; events that are imposed on us. We cannot decide, we cannot think beyond our time and beyond the components of experience itself. We can invent manners to articulate our experiences, to give them a new sense, to construct new stories about them, to dramatize them according to new perspectives, but on the basis of what is given to us, and it is this demand that I have for empiricism: the fact that we do not decide. Philosophy can no longer put itself in the position of thinking the foundation of the world. As Whitehead (1978: 4) says: 'Our datum is the actual world, including ourselves; and this actual world spreads itself for observation in the guise of the topic of our immediate experience. The elucidation of immediate experience is the sole justification for any thought.' Philosophy can no longer ask itself or postulate that it is going to question the conditions of existence of the world. 
The world is there in its factuality, in its contingency, in the stories that it composes, which are contingent stories and events that do not arise out of any a priori necessity. However, once they have taken place, we can no longer deny them and we are indebted to all these contingent events that form our reality. That, for me, is experience: it is the requirement of experience, but by experience I mean this immense source of ideas, stories, theories, including that the whole story of their birth, of their circulation, is contingent and marked with the seal of the event.

By speculation and speculative necessity I mean that demand within experience that - in the milieu of experience, living in the immanence of experience-gives importance, insists on hidden or inaudible possibilities, gives all its importance to the meaning of the 'could-be', of the alternative, which has not been envisaged and which opens our imagination to another possible becoming of our experiences. For me, this is the meaning of the speculative demand. It is the meaning of attention to the fragility of possibilities that is part of our experiences. Speculative empiricism is the demand of contingency. We will never go beyond contingency, as Deleuze and Guattari (1994) said in What Is Philosophy? The great principle of philosophy should be the principle of contingent reason. There is only contingency, but contingency does not mean chaos or disorder. It is the sense of the fragility of the events that have taken place and the events that we inherit - this is fragility. That is, the fact that they could not have taken place but they took place, and that once they have taken place we must take them into account.

The speculative demand is the demand of possibilities, but not a general demand for a theory that would be truer, stronger or more powerful than others; it is the demand of possibilities anchored, present, in our experience. Here is what I tried in two words to relay with these two notions in this oxymoron of speculative empiricism. I think empiricism without speculation would become a blissful testimony [attestation] without openness, without possibility, without resistance to what makes our present. Speculative thinking without experience becomes a kind of formal and normative vision authorizing itself without passing the slightest test. The task of speculative philosophy is to highlight and intensify the possibilities that accompany all experience. As Whitehead (1978: 17) puts it: 'Philosophy is the welding of imagination and common sense into a restraint upon specialists, and also into an enlargement of their imaginations. By providing the generic notions philosophy should make it easier to conceive the infinite variety of specific instances which rest unrealized in the womb of nature.'

\section{ORCID ID}

Thomas Keating (D) https://orcid.org/0000-0003-2334-5987 


\section{Notes}

1. Translation note: parts of this conversation have been translated from French into English. For conceptual terms we have attempted to retain the most direct English translation. In places, where no direct English equivalent was found, we have also kept the original French term in brackets.

2. Translation note: we have chosen to use the word 'manner' for the French manière, which often functions for Debaise (2017a) as a conceptual term concerning, amongst other things, how certain abstractions come to operate on the production of specific modes of thought.

3. After Whitehead, in places Debaise uses 'importance' as a conceptual term referring to 'the manner in which an event crystallizes what is at stake beyond its immediate existence hic et nunc' (2017a: 79). Crucial to this notion of importance is the sense that the value of an event cannot be reduced to a given situation, and thus would also involve the way events produce forms of valuation into the future that are abstracted from their initial moment of actualization. Therefore, 'importance' remains distinct to 'interests', since the latter remains connected to the 'particularity of an event' (p. 79). For more on this distinction between importance and interests, see Debaise (2017a: 79-80).

4. 'You cannot think without abstractions; accordingly, it is of the utmost importance to be vigilant in critically revising your modes of abstraction' (Whitehead, 1948: 59).

\section{References}

Debaise, Didier (2017a) Nature as Event: The Lure of the Possible. Durham, NC: Duke University Press.

Debaise, Didier (2017b) Speculative Empiricism: Revisiting Whitehead. Edinburgh: Edinburgh University Press.

Debaise, Didier (2020) From nature to precarious lives. In: Latour, Bruno, Schaffer, Simon and Gagliardi, Pasquale (eds) A Book of the Body Politic. Cini Foundation, pp. 247-262.

Debaise, Didier and Stengers, Isabelle (2017) The insistence of possibles: Towards a speculative pragmatism. PARSE 7: 13-19.

Deleuze, Gilles and Guattari, Félix (1994) What Is Philosophy? London: Verso. Gibson-Graham, JK (1996) A Postcapitalist Politics. Minneapolis: University of Minnesota Press.

Haraway, Donna (1988) Situated knowledges: The science question in feminism and the privilege of partial perspective. Feminist Studies 14(3): 575-599.

James, William (1920) Collected Essays and Reviews. London: Longmans, Green and Co.

James, William (1996) A Pluralistic Universe. Lincoln: University of Nebraska Press.

Lapworth, Andrew (2015) Beyond bifurcation: Thinking the abstractions of artscience after A.N. Whitehead. Transformations 26: 1-12.

Ruyer, Raymond (2019) The Genesis of Living Forms. London: Rowman \& Littlefield International. 
Savransky, Martin (2019) The pluralistic problematic: William James and the pragmatics of the pluriverse. Theory, Culture \& Society. DOI: 10.1177/ 0263276419848030.

Simondon, Gilbert (2020) Individuation in Light of Notions of Form and Information. Minneapolis: University of Minnesota Press.

Stengers, Isabelle (2015) In Catastrophic Times: Resisting the Coming Barbarism. London: Open Humanities Press.

Viveiros de Castro, Eduardo (2015) Cannibal Metaphysics. Minnesota: University of Minnesota Press.

Whitehead, Alfred North (1948) Science and the Modern World. New York: Mentor.

Whitehead, Alfred North (1978) Process and Reality. New York: The Free Press.

Williams, Nina and Collet, Carole (2020) Biodesign and the allure of 'growmade' textiles: An interview with Carole Collet. GeoHumanities. DOI: 10.1080/2373566X.2020.1816141.

Thomas P. Keating is a post-doctoral researcher in Technology and Social Change at Linköping University's Department of Thematic Studies (TEMA T). His work intersects geography and process philosophies to engage with problems involving human-technology relationships. He has published on the philosophy of Gilbert Simondon, affect, speculative philosophy, and post-humanism. Currently, he is collaborating with Svensk Kärnbränslehantering Aktiebolag in developing speculative thinking through the task of communicating memory of permanent repositories for nuclear waste 100,000 years into the future.

Didier Debaise is a permanent researcher at the Fonds National de la Recherche Scientifique (FNRS) and teaches contemporary philosophy at the Free University of Brussels (ULB). He is the co-founder, with Isabelle Stengers, of the Groupe d'études constructivistes (GECo). His main areas of research are contemporary forms of speculative philosophy, theories of events, and links between American pragmatism and French contemporary philosophy. Two of his books have appeared in English: Nature as Event (Duke University Press) and Speculative Empiricism (Edinburgh University Press). He is currently working on a new book entitled Pragmatique de la terre. 